\title{
Topology Optimization of Gears from Two Wheeler Gear Set Using Parametric Study
}

\author{
Vaibhav Pimpalte ${ }^{1}$, Prof. S.C. Shilwant ${ }^{2}$ \\ ${ }^{I}(P G$ Scholar, PG Scholar, Sinhgad Academy of Engineering/ University of Pune, Maharashtra, India) \\ ${ }_{2}^{2}$ (Professor, Sinhgad Academy of Engineering/ University of Pune, Maharashtra, India)
}

\begin{abstract}
Gears are used to transmit motion from on shaft to another and it has wide variety of applications. One of the applications of gear is in automobile gear box. Gears generally fail when the working stress exceeds the maximum permissible stress. These stresses are proportional to the amount of power transmitted by the gears. This project intends to identify the magnitude of the stresses for a given configuration of a two wheeler gears transmitting power while trying to find ways for reducing weight of the gear. The philosophy for driving this work is the lightness of the gear for a given purpose while keeping intact its functionality thus reducing the material cost of the gear. Ease of incorporating the new feature for weight reduction over the existing process of manufacturing and the magnitude of volume of weight reduced could be considered as the key parameters for assessment for this work.
\end{abstract}

Keywords: Weight optimization, FEA, Spur Gear, Two Wheeler Gear set

\section{Introduction}

Mechanical design can be defined as the selection of materials and geometry, which satisfies, specified and implied functional requirements. The method of design has to minimize the most significant undesirable effect and to maximize the most significant desirable effect. Gears are used for a wide range of industrial applications. They have varied application starting from textile looms to aviation industries. [1] They are the most common means of transmitting power. They change the rate of rotation of machinery shaft and also the axis of rotation. For high speed machinery, such as an automobile transmission, they are the optimal medium for low energy loss and high accuracy. [2] Their function is to convert input provided by prime mover into an output with lower speed and corresponding higher torque or vice-versa. Effective gear design contains Strength, durability, reliability, size, weight and cost.

In this study, gears from two wheeler gear set are analyzed for static loading under the application of tangential load resulting from maximum torque in the given application. After studying the stress distribution on baseline gears, weight reduction areas are identified on given gears and geometrical features are added on the gear to reduce the weight. Static analysis is conducted on the optimized gears under the application of same loading and comparative results are presented about stress distribution between baseline and optimized gears and weight reduction is outlined for each gear of gear set.

\section{Generalized Gear System in Two Wheeler}

Figure 1 below shows the assembly for complete gear transmission system for automobile two wheeler pedal operated system. It uses 5 pairs of spur gear system. From $1^{\text {st }}$ to $5^{\text {th }}$ continuously speed of the vehicle is increased. Gear shift pedal is used to shift the gears and sequence of gear changing is shown in the image below.

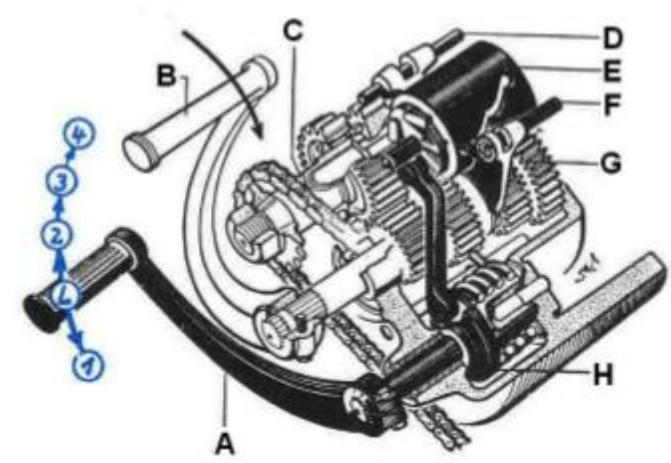

Figure 1: Foot Pedal Operated Gear Transmission System of Two Wheeler 
A $=$ Gear Shift Pedal

$\mathrm{B}=$ Kick Starter

$\mathrm{C}=$ main and clutch shaft

$\mathrm{D} \& \mathrm{~F}=$ Shift forks

$\mathrm{E}=$ shift cam

$\mathrm{G}=$ Start and counter shaft

$\mathrm{H}=$ cam shaft with linkage for shift cam

Most manual transmission two-wheelers use a sequential gearbox. Most modern motorcycles (except scooters) change gears (of which they increasingly have five or six) by foot lever. On a typical motorcycle either first or second gear can be directly selected from neutral, but higher gears may only be accessed in order - it is not possible to shift from second gear to fourth gear without shifting through third gear. A five-speed of this configuration would be known as "one down, four up" because of the placement of the gears with relation to neutral. Neutral is to be found "half a click" away from first and second gears, so shifting directly between the two gears can be made in a single movement.

\subsection{Gear Geometry}

\section{Gear Geometry and Material Properties}

For this study, actual gear set consisting of four gears is considered and CAD model is created by measuring the basic dimensions of each gear in CATIA software.

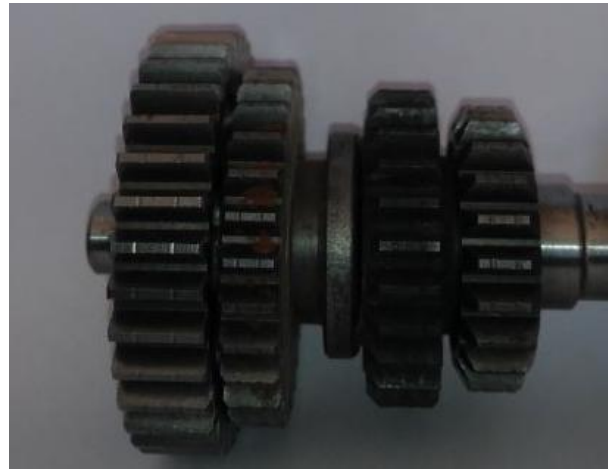

Figure 2: Existing Gear Set

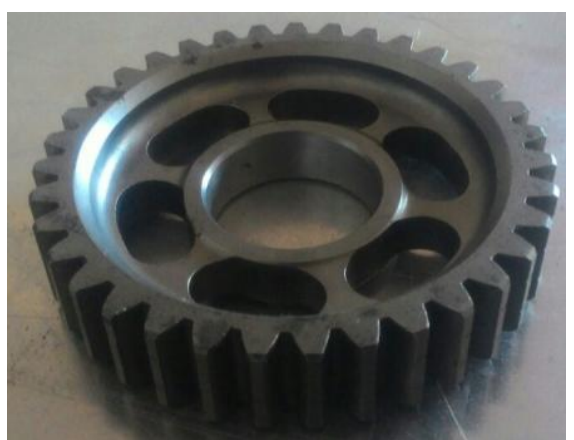

Figure 3: Existing (Baseline) First Gear

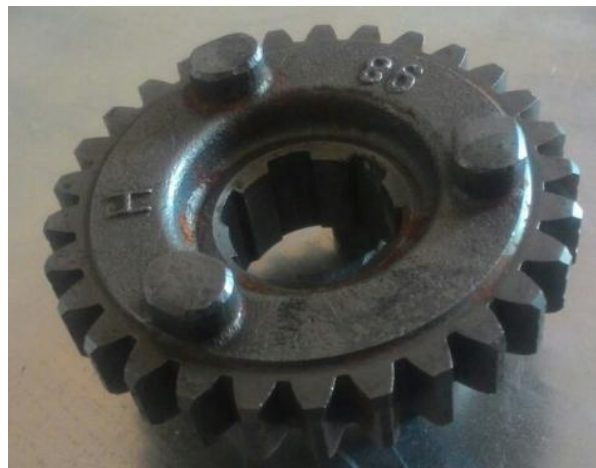

Figure 4: Existing (Baseline) Second Gear 


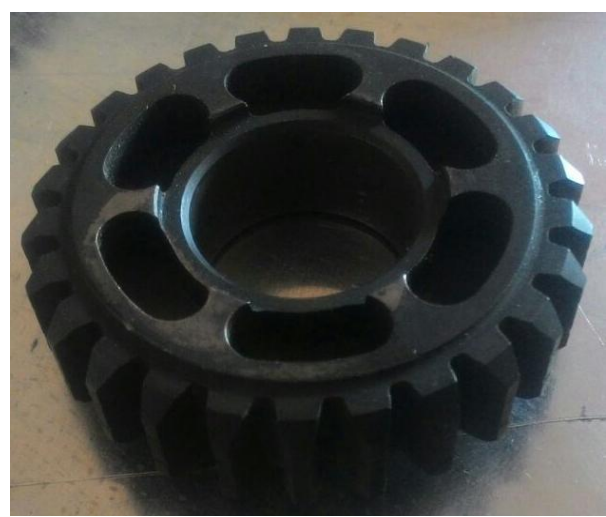

Figure 5: Existing (Baseline) Third Gear

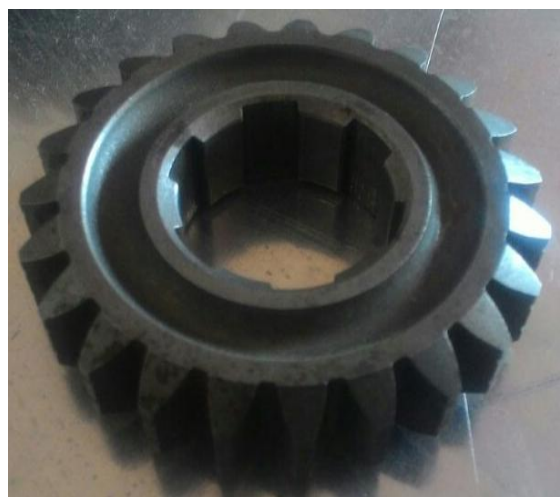

Figure 6: Existing (Baseline) Fourth Gear

\subsection{Material Properties}

For this study, gear material Steel Grade 50C8 is used. Material Properties of 50C8 steel are shown in below table

Table 1: Material Properties

\begin{tabular}{|l|l|}
\hline \multicolumn{2}{|l|}{ Material Properties } \\
\hline Ultimate Tensile Strength (бut) & $965-1030 \mathrm{MPa}$ \\
\hline Compressive Strength $(\sigma \mathrm{c})$ & $862 \mathrm{MPa}$ \\
\hline Young's Modulus (E) & $190-210 \mathrm{GPa}$ \\
\hline
\end{tabular}

Considering the design margin of 3, allowable tensile stress will be $321 \mathrm{MPa}$.

\section{Finite Element Analysis of Baseline Design}

To conduct the FEA analysis, we need geometry of gears, boundary conditions and loads to be applied on gears.

\subsection{Geometry of Baseline Design}

Basic Dimensions of the gear are measured from the actual gear models and CAD model is created in CATIA software through reverse engineering.

\subsection{Boundary Conditions}

Finite Element model is meshed using tetrahedral element of size $3 \mathrm{~mm}$ maximum and 1 to $0.5 \mathrm{~mm}$ in the loading areas and tooth areas for precise results. Other boundary conditions such as fixed support at the inner rim and frictionless support at two faces with loading conditions are shown in below figure.

\subsection{Static Load}

FEA is performed on the gears by calculating the load on the gear resulting from maximum torque condition (10.35 N-m) and applying the calculated load to the one individual teeth of the gear. Stresses on the gears are observed and confirmed to be within the acceptance criteria of $321 \mathrm{MPa}$.

\subsection{FEA Analysis of Baseline Gears}

All four gears are analyzed considering the above mentioned loads and boundary conditions. 


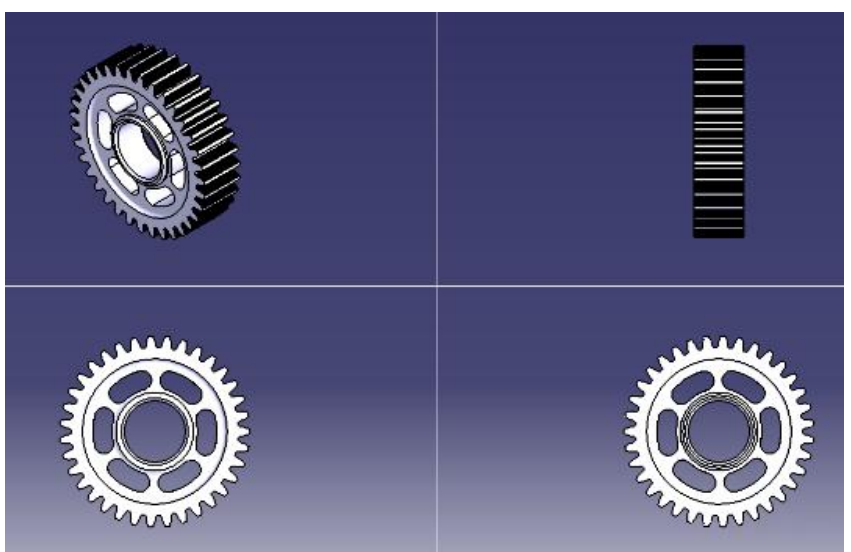

Figure 7 CAD model of $1^{\text {st }}$ baseline gear

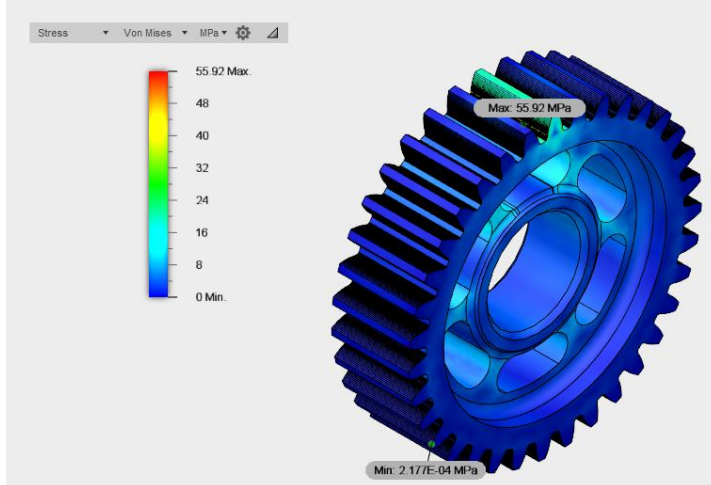

Figure 8 Von Mises stress plot of $1^{\text {st }}$ baseline gear

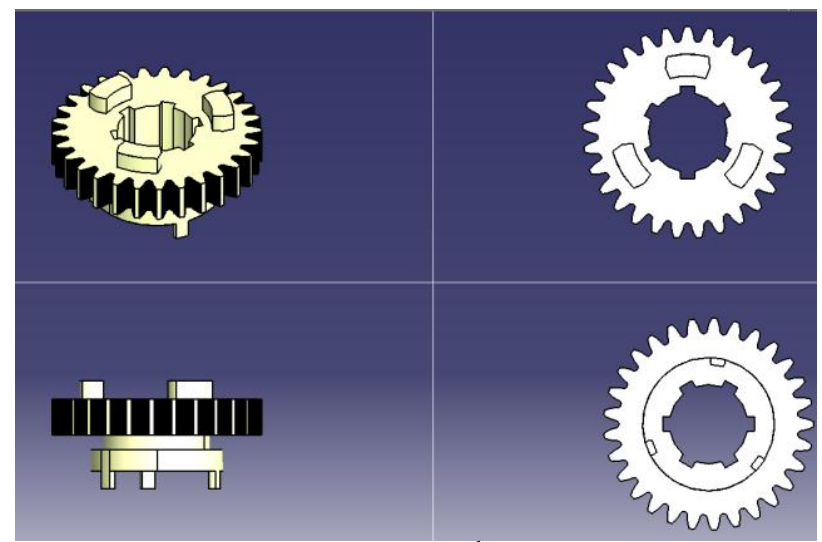

Figure $9 \mathrm{CAD}$ model of $2^{\text {nd }}$ baseline gear

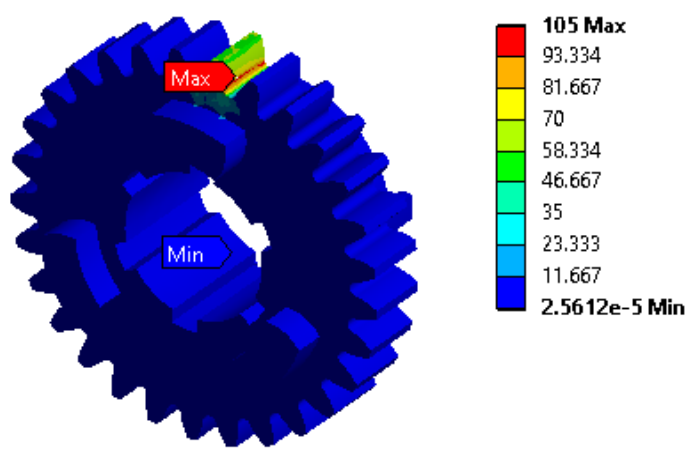

Figure 10 Von Mises stress plot of $2^{\text {nd }}$ baseline gear 


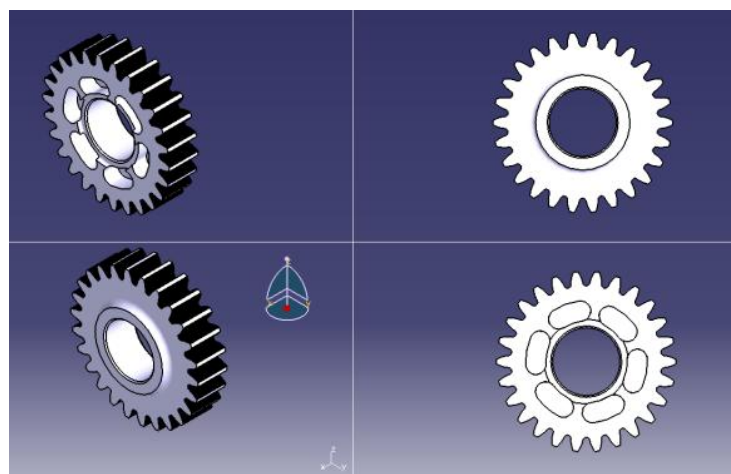

Figure $11 \mathrm{CAD}$ model of $3^{\text {rd }}$ baseline gear

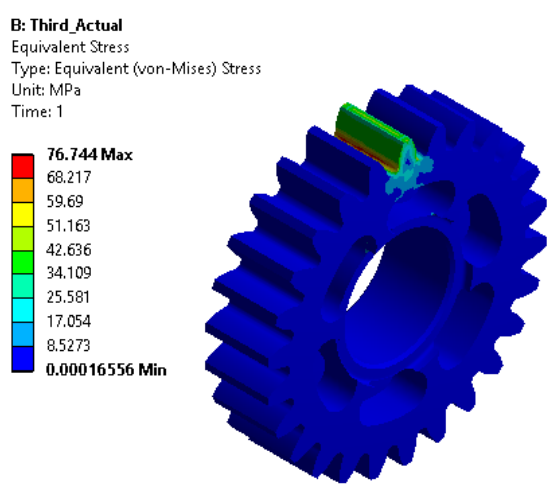

Figure 12 Von Mises stress plot of $3^{\text {rd }}$ baseline gear

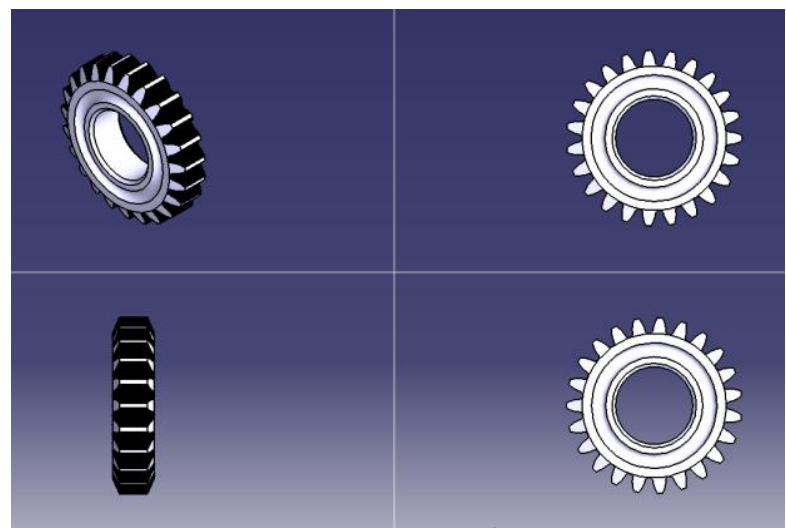

Figure $13 \mathrm{CAD}$ model of $4^{\text {th }}$ baseline gear

G: Fourth_Actual

Equivalent Stress

Unit: $\mathrm{MPa}$

Time: 1

$\left[\begin{array}{r}\mathbf{1 1 6 . 4 6} \text { Max } \\ 103.52 \\ 90.583 \\ -77.643 \\ -64.702 \\ 51.762 \\ 38.821 \\ 25.881 \\ 12.941 \\ \mathbf{0 . 0 0 0 2 4 9 1 9} \text { Min }\end{array}\right.$

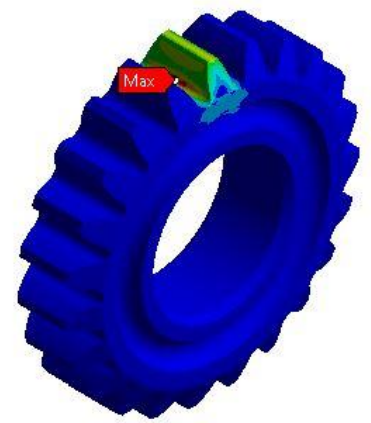

Figure 14 Von Mises stress plot of $4^{\text {th }}$ baseline gear 
Table 2: Stress Values and Weight - Baseline Gears

\begin{tabular}{|l|l|l|}
\hline Gear & $\begin{array}{l}\text { Stress values } \\
(\mathrm{MPa})\end{array}$ & Weight $(\mathrm{Kg})$ \\
\hline Gear-1 & 55.92 & 0.263 \\
\hline Gear-2 & 105 & 0.2 \\
\hline Gear-3 & 76.74 & 0.133 \\
\hline Gear-4 & $116 . .5$ & 0.104 \\
\hline
\end{tabular}

The stress values found from the FEA analysis of baselines gears are well within the acceptance limit of $321 \mathrm{MPa}$. Also looking at the gears geometries, there is scope of design optimization by removing materials from the existing gears. Hence it is decided to look for an opportunity to modify the design for weight reduction without impacting the basic functions of gears.

\subsection{Design Optimization of first gear}

\section{Gear Design Optimization}

Even though the stresses observed in the baseline first gear are low, it can be seen from geometry of the gear that it is already optimized without any further scope of weight reduction. Hence it is decided to not modify the design of the first gear.

\subsection{Design Optimization of Second gear}

Stresses observed in the baseline second gear are well below than the acceptance criteria of $321 \mathrm{MPa}$ and it can be seen that there is a lot of scope of removing material from the geometry of the second baseline gear.

Projections provided on the gear are required and do the important function of assembly of second and third gears; hence we will not change these projections. However, there are low stress regions on the gear which are not important for the gear for functioning or for assembly and materials can be removed from these regions for gear optimization. Below figures shows the design optimization of second gear.

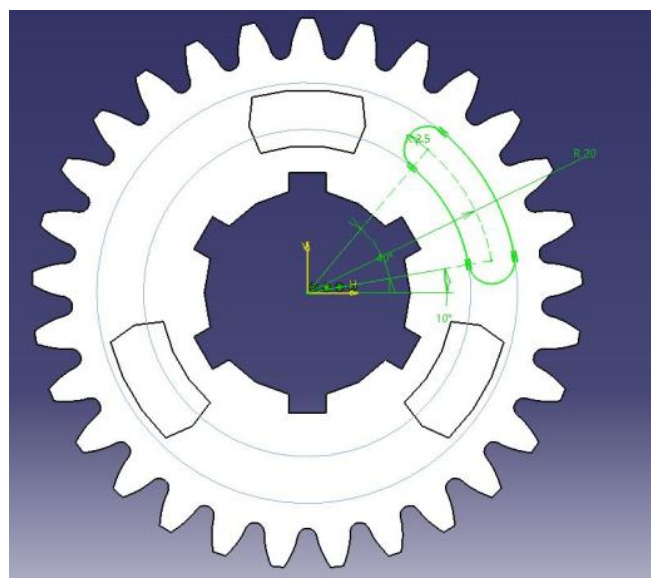

Figure 15 Iteration1-Design optimization sketch of second gear

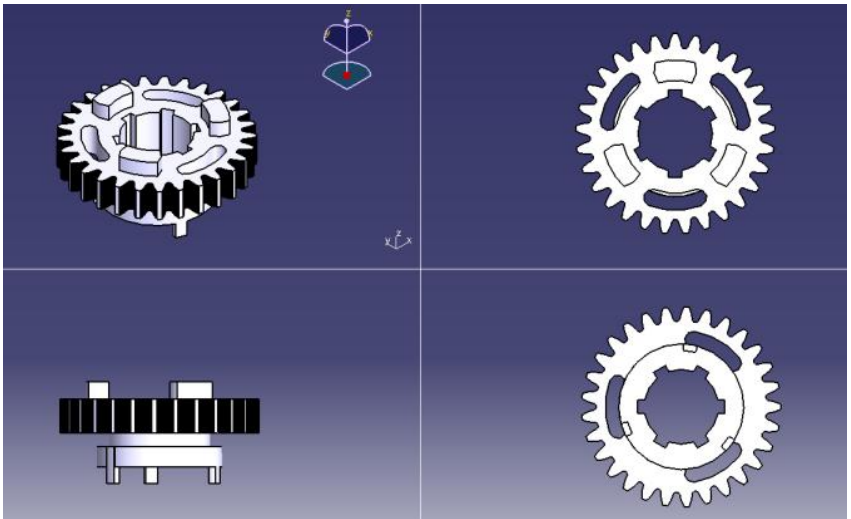

Figure 16 Iteration1- Design optimization of second gear 


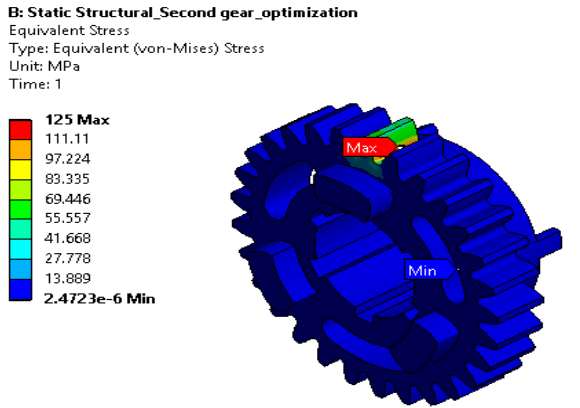

Figure 17 Iteration1- Von Mises stress plot of second gear

Maximum stress observed in the gear is $125 \mathrm{MPa}$ which is well within the acceptance criteria of 321 $\mathrm{MPa}$, so next iteration is performed and further material is removed in the similar pattern by increasing the size of the patterns of material removal. Mass of the Iteration 1 of second gear is $0.179 \mathrm{~kg}$.In iteration2, we will remove some more material from the ieration1 model as stress values from iteration1 are still within the acceptance criteria.

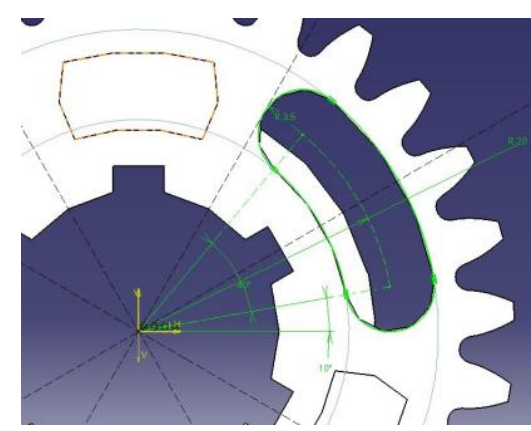

Figure 18 Iteration2-Design Optimization sketch of second gear

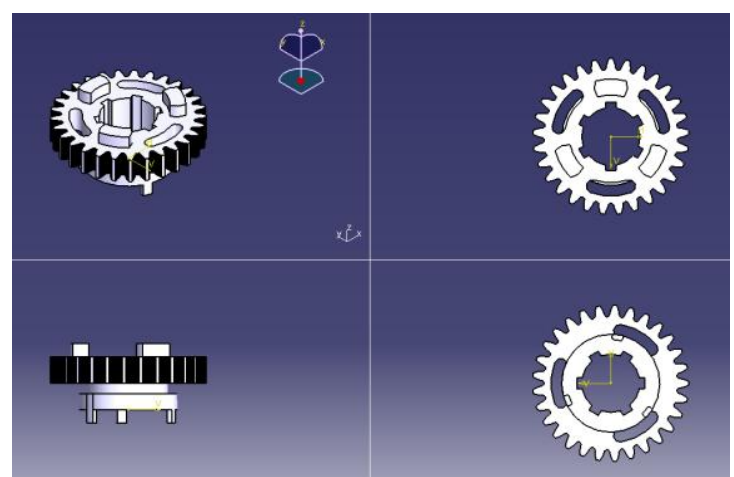

Figure 19 Iteration2- Design Optimization of second gear

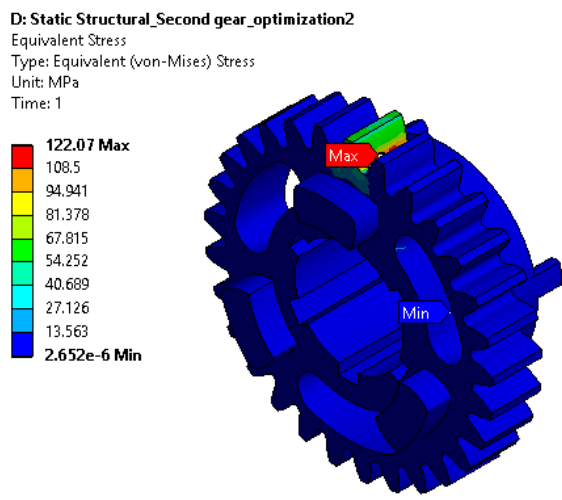

Figure 20 Iteration2- Von Mises stress plot of second gear 
Maximum stress observed in the gear is $122.07 \mathrm{MPa}$ which is well within the acceptance criteria of 321 $\mathrm{MPa}$ but as can be seen from the geometry of iteration 2 gear, there is not further scope of material removal hence it is decided to finalize this iteration. Mass of the Iteration 2 of second gear is $0.168 \mathrm{~kg}$.

\subsection{Design Optimization of Third gear}

Stresses observed on baseline third gear are well below the acceptance criteria hence it is decided to optimize the design of third gear. Below figures shows the design optimization of third gear.

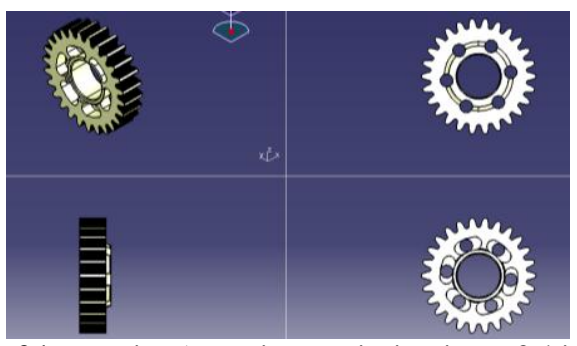

Figure 21 Iteration1-Design optimization of third gear

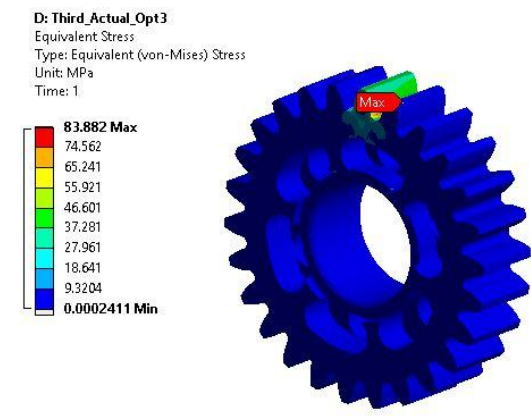

Figure 22 Iteration1 - Von Mises stress plot of third gear

Maximum von Mises stress observed in iteration1 optimization of third gear is $83.882 \mathrm{MPa}$ which is within the acceptance criteria of $321 \mathrm{MPa}$. There is further scope for material removal to reduce the weight of this gear. Figures below shows deign iteration 2 of third gear.

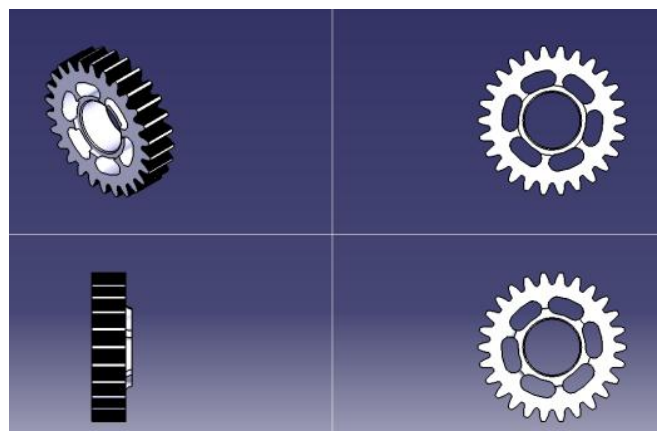

Figure 23 Iteration2-Design Optimization of third gear

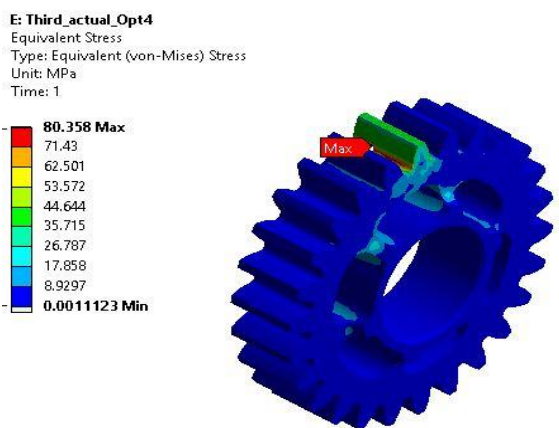

Figure 24 Iteration2- Von Mises stress plot of third gear 
Stresses observed in iteration 2 of third gear are $80.34 \mathrm{MPa}$. As it can be seen in the gear design of iteration 3 there is no more space to remove further material from the gear without affecting the assembly purpose, hence it is decided to not further reduce material from this gear. Total weight of iteration 2 design of third gear is observed as $0.111 \mathrm{~kg}$.

\subsection{Design Optimization of Fourth gear}

In the gear 4 baseline design FEA results, we have observed that maximum stress that is observed in the gear due to torque at one tooth is $116.5 \mathrm{MPa}$. Maximum stress is well within the acceptance criteria for the gear material of $321 \mathrm{MPa}$. It can be seen from the Stress plot that there is good possibility of removing material without affecting the gear's capacity to withstand the torque. Iteration 1 design is generated by removing some material from the recess observed in baseline design. Figures below shows design iterations for optimization of fourth gear.

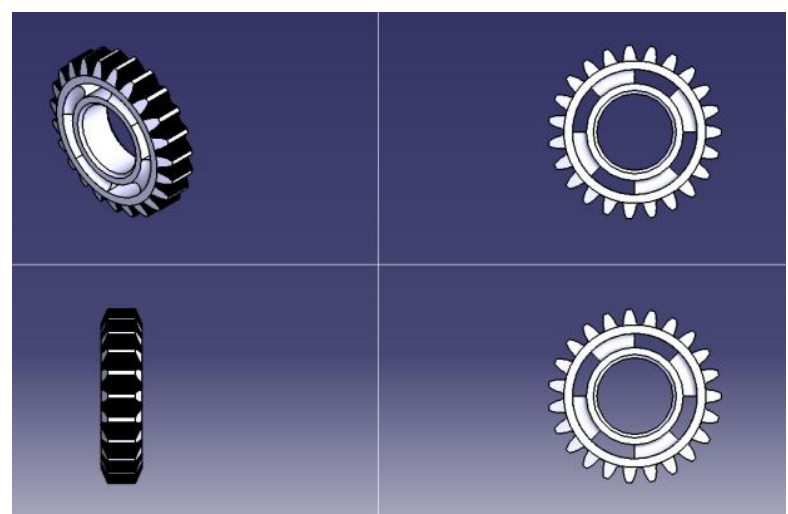

Figure 25 Iteration1-Design optimization of fourth gear

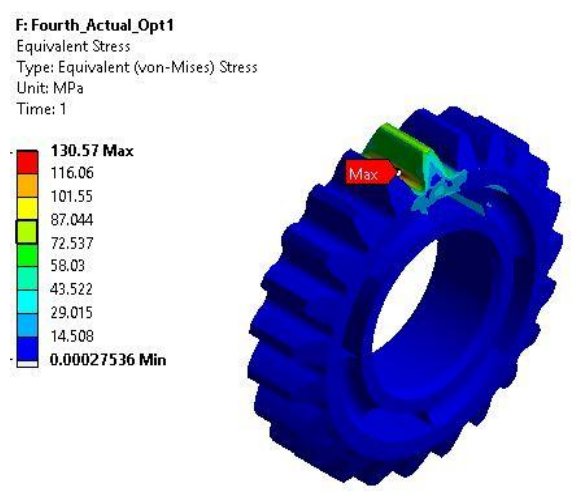

Figure 26 Iteration1- Von Mises stress plot of fourth gear

Iteration 1design FEA shows that maximum stress observed at the gear is $130.57 \mathrm{MPa}$. Maximum stress is within the acceptance criteria and there is still more scope to remove material without disturbing assembly and purpose of the gear. Hence, iteration 2 will be performed to remove further more material from the current design.

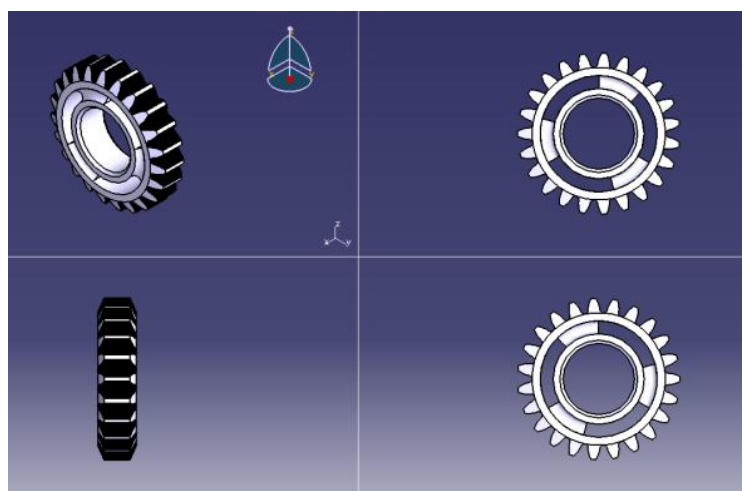

Figure 27 Iteration2-Design optimization of fourth gear 


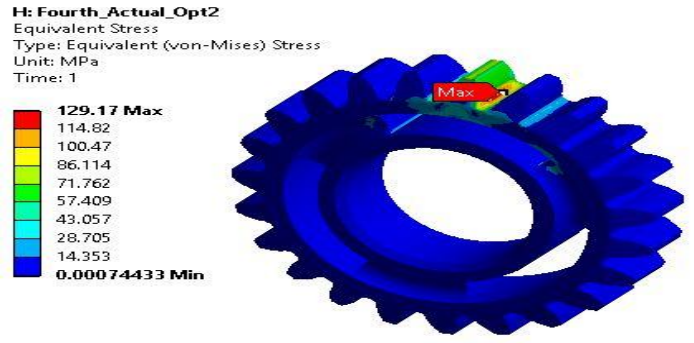

Figure 28 Iteration2- Von Mises stress plot of fourth gear

Iteration 2 FEA shows that maximum stress observed at the gear is $129 \mathrm{MPa}$. Maximum stress is within the acceptance criteria but there is no more scope to remove material without disturbing assembly and purpose of the gear. Hence, it is decided not to further modify the geometry of gear. Mass of the Iteration 2 design is $0.0875 \mathrm{~kg}$.

VI. Results \& Discussion

Comparative results between baseline design and optimized design is shown below in table 3 and 4 .

Table 3: Comparative results between Baseline and Optimized Design (Stress Values)

\begin{tabular}{|l|l|l|l|}
\hline Gear & $\begin{array}{l}\text { Baseline } \\
\text { Design- Stress } \\
\text { values }(\mathrm{MPa})\end{array}$ & $\begin{array}{l}\text { Optimized } \\
\text { Design- Stress } \\
\text { Values }(\mathbf{M P a})\end{array}$ & $\begin{array}{l}\text { Increase in } \\
\text { stresses }\end{array}$ \\
\hline Gear-1 & 55.92 & - & - \\
\hline Gear-2 & 105 & 122.07 & 16.25 \\
\hline Gear-3 & 76.74 & 80.34 & 4.69 \\
\hline Gear-4 & $116 . .5$ & 129 & 10.72 \\
\hline
\end{tabular}

Table 4: Comparative results between Baseline and Optimized Design (Weight)

\begin{tabular}{|l|l|l|l|}
\hline Gear & $\begin{array}{l}\text { Baseline } \\
\text { Design-Weight } \\
(\text { Kg) }\end{array}$ & $\begin{array}{l}\text { Optimized } \\
\text { Design- } \\
\text { Weight }(\text { Kg })\end{array}$ & $\begin{array}{l}\text { \% Decrease in } \\
\text { weight }\end{array}$ \\
\hline Gear-1 & 0.263 & - & - \\
\hline Gear-2 & 0.2 & 0.168 & 16 \\
\hline Gear-3 & 0.133 & 0.111 & 16.54 \\
\hline Gear-4 & 0.104 & 0.0875 & 15.86 \\
\hline
\end{tabular}

As can be seen from results tables $3 \& 4$, there is significant weight reduction is possible on gear $2,3 \& 4$ under the application of static loading without much affecting the functionality of the gear and keeping the stresses within the acceptable limit.

\section{Conclusion}

This paper showcases a general view of mass optimization of spur gear under static loading. It states Finite element analysis method for the spur gear tooth using ANSYS 16. It further studies the mass of spur gear with inclusion of different geometries. The results show that, it is possible to reduce the weight of these gears without much increase in stresses and keeping the functionality of gears intact.

\section{References}

[1]. Mr. Bhatt Parth Jitendrabhai "A Review on Design, Analysis and Material Optimization of High Speed Helical Gear by Changing Different Design Parameters Using FEA Approach”, International Journal of Engineering Sciences \& Research Technology.

[2]. Sarfraz Ali N. Quadri, Dhanajay R. Dolas "Mass Reduction of Involute Spur Gear under Static Loading “American Journal of Mechanical Engineering and Automation.

[3]. Mr. S. Padmanabhan, Mr. S. Ganeshan, Mr. M. Chandrasekaran, and Mr. V. Srinivasa Raman, "Gear Pair Design Optimization by Genetic Algorithm and FEA", Department Of Mechanical and Production Engineering, Sathyabama University, Chennai, India.

[4]. Mr. Sa'id Golabi, Mr. Javad Jafari Fesharaki, Mrs. Maryam Yazdipoor "Gear Train Optimization Based On Minimum Volume/Weight Design by Using the Mat lab Program” Mechanism And Machine Theory 73 (2014) 197-217.

[5]. Mr. Nenad Marjanovic, Mr. Biserka Isailovic, Mr. Vesna Marjanovic, Mr. Zoran Milojevic, Mr. Mirko Blagojevic, Mr. Milorad Bojic “A Practical Approach To The Optimization Of Gear Trains With Spur Gears" Mechanism And Machine Theory 53 (2012) $1-16$.

[6]. Mr. Ram Krishna Rathore And Mr. Abhishek Tiwari, "Bending Stress Analysis \& Optimization Of Spur Gear", International Journal Of Engineering Research \& Technology (IJERT), Vol. 3 Issue 5, May - 2014, Issn: 2278-0181 Vol. 3 Issue 5.

[7]. Mohd. Muzammil, Prem Pal Singh and Faisal Talib, “Optimization of Gear Blank Casting Process by Using Taguchi's Robust Design Technique”, Department of Mechanical Engineering, Aligarh Muslim University, Aligarh, India.

[8]. P B Pawar ,Abhay A Utpat “Analysis of Composite Material Spur Gear under Static loading Condition”, SVPM's ITE Malegaon (BK), Baramati. 